\title{
Clinical-pathological features and treatment of acute appendicitis in the very elderly: an interim analysis of the FRAILESEL Italian Multicentre Prospective Study
}

\section{Pietro Fransvea}

Università degli Studi di Roma La Sapienza https://orcid.org/0000-0003-4969-3373

Valeria Fico

Emergency Surgery and Trauma, Fondazione Policlinico Universitario A. Gemelli IRCCS

Valerio Cozza

Emergency Surgery and Trauma, Fondazione Policlinico Universitario A. Gemelli IRCCS

\section{Gianluca Costa}

Azienda Ospedaliera Sant'Andrea

\section{Luca Lepre}

Azienda Sanitaria Locale Roma 1

\section{Paolo Mercantini}

Azienda Ospedaliera Sant'Andrea

\section{Antonio La Greca}

Emergency Surgery and Trauma, Fondazione Policlinico Universitario A. Gemelli IRCCS

Gabriele Sganga ( $\sim$ gabriele.sganga@policlinicogemelli.it)

https://orcid.org/0000-0001-5079-0395

\section{Research article}

Keywords: acute appendicitis, elderly, very elderly

Posted Date: July 15th, 2020

DOI: https://doi.org/10.21203/rs.3.rs-42233/v1

License: (c) (i) This work is licensed under a Creative Commons Attribution 4.0 International License. Read Full License

Version of Record: A version of this preprint was published at European Journal of Trauma and Emergency Surgery on March 18th, 2021. See the published version at https://doi.org/10.1007/s00068-021-01645-9. 


\section{Abstract \\ Background}

emergency abdominal surgery in the elderly represents a global issue. Diagnosis of AA in old patients is often more difficult. Appendectomy remains the gold standard of treatment and, even though it is performed almost exclusively with a minimally invasive technique, it can still represent a great risk for the elderly patient, especially above 80 years of age. A careful selection of elderly patients to be directed to surgery is therefore fundamental. The primary aim was to critically appraise and compare the clinical-pathological characteristics and the outcomes between oldest old ( $\geq 80$ years) and elderly (65-79 years) patients with Acute Appendicitis (AA).

\section{Methods}

The FRAILESEL is a large, nationwide, multicenter, prospective study investigating the perioperative outcomes of patients aged $\geq 65$ years who underwent emergency abdominal surgery. Particular focus has been directed to the clinical and biochemical presentation as well as to the need for operative procedures, type of surgical approach, morbidity and mortality, and in-hospital length of stay. Two multivariate logistic regression analyses were performed to assess perioperative risk factors for morbidity and mortality.

\section{Results}

182 patients fulfilled the inclusions criteria. Mean age, ileocecal resection, OAD and ASA score $\geq 3$ were related with both overall and major complication. The multivariate analysis showed that MPI and complicated appendicitis were independently factors associated with overall complications. OAD and ASA score $\geq 3$ were independently factors for both overall and major complications.

\section{Conclusions}

age $\geq 80$ years is not an independent risk factor for morbidities. POCUS is safe and effective for the diagnosis; however, a CECT is often needed Having the oldest old a smaller functional organ reserve, an earlier intervention is needed, especially because they required greater rate of major resection.

\section{Introduction}

As the world population is aging rapidly, emergency abdominal surgery for acute abdomen in the elderly represents a global issue, both in developed and developing countries. (1-4) More than $20 \%$ of the Italian population is over the age of 65 and, by the year 2050, this percentage is expected to grow to $34 \%$. Over the last 20 years, country's life expectancy has increased from 78 to 80 years for men and from 84 to 85 years for women. It is estimated that $21 \%$ of the total population older than 60 years will require surgery, compared with only $12 \%$ of people in the $45-60$ age group. $(5,6)$ Demographic changes in the population have also modified the profile of emergency abdominal surgery, where typical causes of acute abdomen in the elderly include acute 
cholecystitis, incarcerated hernia, bowel obstruction, acute diverticulitis and acute appendicitis $(A A)$. $(7,8)$ AA is the most common general surgical emergency worldwide, but its diagnosis remains challenging. $(9,10)$ When compared to the general population, diagnosis of AA in old patients is often more difficult. (11) Older patients generally present later in the course of the disease and may have nonspecific symptoms. (12-13) To improve diagnosis of appendicitis, international guidelines recommend routine clinical risk scoring. $(14,15)$ Although the Appendicitis Inflammatory Response (AIRS) and Alvarado scores are recommended most frequently, no one of these score is widely used in clinical practice and none is specific for elderly patients. (16-19) In addition, their higher comorbidity rate and the less systemic reserve capacity may potentially lead to severe consequences in case of such an acute event. They often have other conditions such as diverticulitis or neoplasms that can mimic acute appendicitis. (20) Appendectomy remains the gold standard of treatment and, even though it is now performed almost exclusively with a minimally invasive technique, it can still represent a great risk for the elderly patient, especially above 80 years of age and in the event of multiple comorbidities. $(14,21,22,23)$ A careful selection of elderly patients to be directed to surgery versus those who can benefit only from antibiotic therapy is therefore fundamental, since if a "white" appendectomy rate is acceptable in young people, especially in women, this cannot be reproduced in the elderly because they have not the same ability to tolerate the stress induced by the surgical procedure. $(1,24)$ In this study, we focus our attention on the subgroup over 80 years old compared to the subgroup of elderly patient between 65-79 years old. The primary aim was to analyse the difference between the two groups in the clinical-pathological data, management strategies, and in the shortterm outcomes after emergency surgery for Acute Appendicitis

\section{Materials And Methods:}

\section{Study settings and protocol}

This report originates from the FRAILESEL (Frailty and Emergency Surgery in the Elderly) study (ClinicalTrials.gov identifier: NCT02825082) $(8,23,24)$. The FRAILESEL is a large, nationwide, multicenter, prospective study that investigated the perioperative outcomes of patients aged $\geq 65$ years who underwent emergency abdominal surgery over a period of consecutive 18 months (January 2017 and June 2018). Data regarding elderly patients discharged from the participating centers were prospectively collected. Centres were included on a volunteer basis, and neither investigators nor participating hospitals were paid for their collaboration. Clinical decisions, including operative technique, were based on the criteria of individual centers and attending surgeons. The investigators were informed about the objectives of the study and asked for complete details about the surgical management of acute abdomen in the elderly following standard methods and collection protocols.

The final FRAILESEL Study protocol was approved by the Ethics Committee of Sapienza University and of all the centers and by the boards of the involved societies. All parts of the study and the present manuscript have been checked and presented according to the checklist for (STROBE) (25).

\section{Exclusion criteria and collected data confirmation}

Exclusion criteria were the following: patients younger than 65 years old at the day of surgery; diagnostic laparoscopy/laparotomy with no further surgical procedures performed with the exception of intestinal ischemia; lack of informed consent for the study participation; endoscopic procedures and emergency 
reoperations after elective surgery; patients already hospitalized and scheduled for the same procedure; patients participating in another trial. Submissions made by unconfirmed participants, duplicate submissions, record with more than $5 \%$ of missing data, and data submitted by residents from dual or more residency programs were excluded. Although demographic information was collected on the patients, all data were anonymized before analysis even for center identification. The FRAILESEL study encompassed the final enrollment of 2635 patients but 2563 with confirmed data.

\section{Patients characteristics, preoperative variables and objectives of this study}

The FRAILESEL study investigates over 130 variables, exploring five domains such as patient demographic and clinical data, preoperative risk factors and operative variables, frailty condition, and postoperative outcomes and follow-up. Data collected included patient demographic characteristics (age, gender, weight, height), medical and surgical history (comorbidities), common preoperative biochemical blood examination (including CRP, PCT and arterial blood gas analysis), pathological features, and operative details. Comorbidity was recorded if the condition was being medically treated at the time of admission, or if previous treatment for the condition was described in the admission report. Preoperative risk was assessed with anesthesiologist-assigned American Society of Anesthesiologists (ASA) class. Frailty was assessed by calculating the 5 modified Frailty Index (5$\mathrm{mFI}$ ) as described by Tracy et al. (26) The Mannheim Peritonitis Index (MPI) was also calculated. (27) Systemic inflammatory response syndrome (SIRS) and quick-Sofa (q-Sofa) were also evaluated. Postoperative complications have been reported and categorized according to the Clavien-Dindo (CD) classification system by the study leader in each of the participating centers. (28) Morbidity and mortality have been considered regardless of the time elapsed from the surgical procedure if reasonably related to it. With regard to the aims of the present study, patients were selected from the dataset using the International Classification of Diseases versions 9 (ICD-9 ${ }^{\text {TM }}$ ) (codes 540.xx to 543.xx). After the final revision, appendicitis due to neoplastic lesion and incidental appendectomy were excluded. Primary aim was to critically appraise and compare the clinicalpathological characteristics and the outcomes between oldest old ( $\geq 80$ years) and elderly (65-79 years) patients with a diagnosis of AA. Particular focus has been directed to the clinical and biochemical presentation as well as to the need for operative procedures, type of surgical approach, morbidity and mortality rate, and length of in-hospital stay (LOS). An open conversion was defined as when a procedure was attempted via the minimally invasive approach but required an open incision to be completed. The decision for preoperative workup was made by the attending surgeon and/or the attending emergency physician. Computerized tomography scan was performed with intravenous contrast material (CECT). Results of CECT scans and point-of-careultrasound (POCUS) were interpreted by a staff radiologist. Diagnosis of AA was made by the appearance of the appendiceal wall and by the presence of peri-cecal or peri-appendicular inflammation with or without intraabdominal fluid collection. Complicated appendicitis was defined by the finding of a gangrenous or perforated appendix, as well as the presence of an intra-abdominal abscess. CECT was considered positive only when there could be no diagnostic doubts or differential diagnosis (e.g. pseudo-inflammatory tumours, abscess). Secondary aim was to determine the frequencies of elderly with acute appendicitis and the elderly to oldest old patient ratio. For this purpose, we randomly selected 19 centres and asked the principal investigator in each centre to select the total number of patients with acute appendicitis submitted to surgery in the study period. Eleven centres were able to provide the requested data.

\section{Statistical analysis}


Statistical analysis was performed with SPSS software, version 21 (IBM, New York, NY - USA) for MacOSX. Dichotomous data and counts were presented in frequencies, whereas continuous data were presented as mean values \pm standard deviations and/or median with Interquartile Range (IQR). Differences between means were compared using the independent sample Student's t-test or the Mann-Whitney U test when indicated. Fisher's exact test or $\chi^{2}$ test, with or without Yates correction, were implemented to compare differences in frequencies. Two further multivariate logistic regression analyses were performed in order to assess perioperative risk factors for morbidity and mortality. All variables with $p$ value $<0.20$ at univariate analysis were entered into a multivariate model. A $p$ value $\leq 0.05$ was considered statistically significant.

\section{Results}

During the study period, 182 patients underwent emergency surgery procedure for acute appendicitis, fulfilled the inclusion criteria for this study. Table 1 reports patients' characteristics in detail. The overall median age was $74.5 \pm 7.3$ years and there was a male predominance (141 male patients, $77.5 \%)$. Of these, 41 (22,5\%) were aged $\geq 80$ years and constituted the oldest old Group (OOG); the remaining $141(77,9 \%)$ patients had an age between 65 and 79 years and represented the Control Elderly Group (CEG). Table 1 shows also the comparison between the OOG and the CEG group. In the oldest old, $75.6 \%$ were male, and we observed the same male/female ratio in CEG with $78.0 \%$ of male. The survey revealed that the overall mean rate of elderly patients with acute appendicitis was $10.7 \%$ (range: $4.6-14.2 \%$ ), while the mean rate of oldest old patients was $23.8 \%$ (range: 19.4-26.3\%). Overall severe frailty rate was 50.5\%; although slightly higher in the OOG, frailty rates were not statistically different between the two groups, being present as severe in $61.0 \%$ in the oldest old group, and $47.5 \%$ in the control elderly group. 
Table 1

Patients clinical features

\begin{tabular}{|c|c|c|c|c|c|c|c|c|}
\hline & & Total & $\%$ & $\begin{array}{l}\text { Oldest } \\
\text { old }\end{array}$ & $\%$ & $\begin{array}{l}\text { Elderly } \\
<80\end{array}$ & $\%$ & $\begin{array}{l}P \\
\text { value }\end{array}$ \\
\hline Number of Patients & & 182 & & 41 & & 141 & & \\
\hline Age Mean (SD) & & $\begin{array}{l}74.5 \pm \\
7.3\end{array}$ & & $\begin{array}{l}85.5 \pm \\
4.3\end{array}$ & & $\begin{array}{l}71.3 \pm \\
4.0\end{array}$ & & ¿.001 \\
\hline Median (IQR) & & $\begin{array}{l}74(65- \\
95)\end{array}$ & & $\begin{array}{l}84(80- \\
95)\end{array}$ & & $\begin{array}{l}71 \\
(65- \\
79)\end{array}$ & & \\
\hline \multirow[t]{2}{*}{ Sex } & Female & 41 & $22.5 \%$ & 10 & $24.4 \%$ & 31 & $22.0 \%$ & 0.91 \\
\hline & Male & 141 & $77.5 \%$ & 31 & $75.6 \%$ & 110 & $78.0 \%$ & \\
\hline BMI & & $\begin{array}{l}26.13 \pm \\
4.7\end{array}$ & & $\begin{array}{l}24.9 \pm \\
4.2\end{array}$ & & $\begin{array}{l}26.5 \pm \\
4.8\end{array}$ & & 0.98 \\
\hline Frailty & & & & & & & & 0.18 \\
\hline $\begin{array}{l}5 \text {-mFI 0/0.2 (not or } \\
\text { moderate frailty) }\end{array}$ & & 90 & $49.5 \%$ & 16 & $39.0 \%$ & 74 & $52.5 \%$ & \\
\hline $\begin{array}{l}5-\mathrm{mFI} \geq 0.4 \text { (severe } \\
\text { frailty) }\end{array}$ & & 92 & $50.5 \%$ & 25 & $61.0 \%$ & 67 & $47.5 \%$ & \\
\hline Temperature & & $\begin{array}{l}37.3 \pm \\
0.8\end{array}$ & & $\begin{array}{l}37.2 \pm \\
0.9\end{array}$ & & $\begin{array}{l}37.3 \pm \\
0.8\end{array}$ & & 0.40 \\
\hline WBC & & $\begin{array}{l}13.2 \pm \\
4.4\end{array}$ & & $\begin{array}{l}11.3 \pm \\
3.2\end{array}$ & & $\begin{array}{l}13.7 \pm \\
4.6\end{array}$ & & 0.35 \\
\hline PCR & & $7.4 \pm 8.2$ & & $\begin{array}{l}8.6 \pm \\
8.6\end{array}$ & & $\begin{array}{l}7.0 \pm \\
8.0\end{array}$ & & 0.50 \\
\hline Creatinine & & $\begin{array}{l}1.15 \pm \\
0.8\end{array}$ & & $\begin{array}{l}1.5 \pm \\
1.2\end{array}$ & & 1.00 .5 & & $\hat{0} .05$ \\
\hline Glicemia & & $\begin{array}{l}134.6 \pm \\
61.3\end{array}$ & & $\begin{array}{l}138.3 \pm \\
97.3\end{array}$ & & $\begin{array}{l}133.5 \\
\pm 46.3\end{array}$ & & 0.18 \\
\hline Lactate & & $0.9 \pm 1.7$ & $31.3 \%$ & $\begin{array}{l}2.0 \pm \\
3.9\end{array}$ & & $\begin{array}{l}0.6 \pm \\
0.8\end{array}$ & & $\hat{0} .05$ \\
\hline \multirow[t]{2}{*}{ SIRS } & Yes & 41 & $22.5 \%$ & 7 & $17.1 \%$ & 34 & $24.1 \%$ & 0.46 \\
\hline & No & 141 & $77.5 \%$ & 34 & $82.9 \%$ & 107 & $75.9 \%$ & \\
\hline $\begin{array}{l}\text { Mannheim Peritonitis } \\
\text { Index }\end{array}$ & & $\begin{array}{l}10.5 \pm \\
5.0\end{array}$ & & $\begin{array}{l}10.8 \pm \\
5.9\end{array}$ & & $\begin{array}{l}10.4 \pm \\
4.8\end{array}$ & & 0.082 \\
\hline \multirow[t]{2}{*}{ Comorbidity } & Yes & 153 & $84.1 \%$ & 35 & $85.4 \%$ & 118 & $83.7 \%$ & 0.98 \\
\hline & No & 29 & $15.9 \%$ & 6 & $14.6 \%$ & 23 & $16.3 \%$ & \\
\hline \multirow[t]{2}{*}{ Diabetes } & Yes & 43 & $23.6 \%$ & 13 & $31.7 \%$ & 30 & $21.3 \%$ & 0.32 \\
\hline & No & 139 & $76.4 \%$ & 28 & $68.3 \%$ & 111 & $78.7 \%$ & \\
\hline
\end{tabular}




\begin{tabular}{|lllllllll|}
\hline & & Total & $\%$ & $\begin{array}{l}\text { Oldest } \\
\text { old }\end{array}$ & $\%$ & $\begin{array}{l}\text { Elderly } \\
<80\end{array}$ & $\begin{array}{l}\text { P } \\
\text { value }\end{array}$ \\
\hline \multirow{2}{*}{ Oral anticoagulant drugs } & Yes & 46 & $25.3 \%$ & 11 & $26.8 \%$ & 35 & $24.8 \%$ & 0.79 \\
\cline { 2 - 5 } & No & 136 & $74.7 \%$ & 30 & $73.2 \%$ & 106 & $75.2 \%$ & \\
& 1 & 11 & $6.0 \%$ & 1 & $2.4 \%$ & 10 & $7.1 \%$ & 0.35 \\
& 2 & 65 & $35.7 \%$ & 13 & $31.7 \%$ & 52 & $36.9 \%$ & \\
& 3 & 99 & $54.4 \%$ & 24 & $58.5 \%$ & 75 & $53.2 \%$ \\
& 4 & 6 & $3.3 \%$ & 3 & $7.3 \%$ & 3 & $2.1 \%$ \\
\hline
\end{tabular}

We evidenced no differences between the two groups in terms of comorbidities, diabetes and use of Oral Anticoagulant Drugs (OAD), Body Mass Index (BMI), Body Temperature (BT). Regarding pre-operative biochemical values, the $O O G$ show higher creatinine levels $(1.5 \pm 1.2$ vs $1.0 \pm 0.5, p<0.05)$ and higher lactate level $(2.0 \pm 3.9$ vs $0.6 \pm 0.8 p<0.05)$ compared to the CEG. However, no differences were evidenced between the two groups in terms of SIRS (7 patients, $17.1 \%$ vs 34 patients, $24.1 \%$ in the OOG compared to CEG, respectively; $p=0.46$ ) and q-SOFA (9 patients $21,9 \% \%$ vs $3726,2 \%$ patients in the OOG compared to CEG, respectively; $p=$ 0.51) According to the Mannheim Peritonitis Index, the oldest old showed a slightly more severe peritonitis but not statistically significant ( $10.8 \pm 5.9$ vs $10.4 \pm 4.8$, in the OOG compared to $C E G$, respectively; $p=0,082)$. The overall mean American Society of Anaesthesiology (ASA) score was ASA 3 (99 patients, $54.4 \%$ ) followed by ASA 2 (66 patients, 35.7\%). The same distribution of patients according to the ASA score was observed in the two groups, with no statistically significant differences $(p=0,35)$. Under the clinical point of view, a POCUS was performed in 106 patients $(58,2 \%)$ and a CECT of the abdomen was performed in 149 patients $(81,9 \%)$. Of note POCUS was positive for acute appendicitis in $66 \%$ of the cases with no difference between the two groups while CT scan was positive in almost all the patients $(85,9 \%)$. A clinical picture of complicated appendicitis was highlighted in the $34.6 \%$ patients with a slightly higher rate in the CEG (46 patients, $32,6 \%$ vs 17 patients, 4155 , in the CEG compared to $00 \mathrm{OG}$, respectively; $p=0.3$ ). Table 2 summarized the pre-operative data and outcomes. All but seven patients underwent surgical procedure (175 patients, $96.7 \%$ ) with just one negative exploration ( $0.5 \%)$. Of these seven patients, $6(3,3 \%)$ underwent a pure non-operative management with only antibiotic therapy and one $(0,5 \%)$ underwent percutaneous drainage associated with antibiotic therapy. Even if it is not possible to make a statistical comparison, we want to underline how 6 out of the 7 conservative treatments belonged to the Oldest Old Group. Appendectomy was performed in 129 (91.5\%) of the CEG patients while it was performed in $75,6 \%$ of the OOG. The difference was statistically significant $(p<0,05)$, even if most of the ileocecal resection were performed in the CEG without statistical significance ( $9.8 \%$ vs $7,1 . \%$ in the $00 \mathrm{G}$ compared to CEG respectively $p=0,39$ ). More specifically, a laparoscopic approach was most commonly adopted in the CEG group (100 patients $-70,9 \%)$ as compared to the OOG $(13$ patients $-31,7 \%)(p<0.05)$. However, there was no statistically significant difference regarding the conversion rate between the two groups (4 patients, $30,8 \%$ vs 16 patients, 15,8 . \% in the OOG compared to CEG, respectively, $p=0,39$ ). There was no difference in terms of morbidity, Surgical Site Infections (SSI), intra-abdominal abscess and mortality, with an overall morbidity and mortality rate of 64 patients, $35.2 \%$ and 2 patients, $1,1 \%$ respectively. The univariate and multivariate analysis for overall and major complications are showed in Table 3. At univariate analysis, factors related to both overall 
and major complication were mean age, ileocecal resection, OAD and ASA score $\geq 3$. The multivariate analysis showed that MPI and complicated appendicitis were independently factors associated with overall complications while higher INR value was independently associated with major complications. Moreover, OAD and ASA score $\geq 3$ were independently factors associated with both overall and major complications. 
Table 2

perioperative variable and outcomes

\begin{tabular}{|c|c|c|c|c|c|c|c|c|}
\hline & & Total & $\%$ & $\begin{array}{l}\text { Oldest } \\
\text { old }\end{array}$ & $\%$ & $\begin{array}{l}\text { Elderly } \\
<80\end{array}$ & $\%$ & $\begin{array}{l}P \\
\text { value }\end{array}$ \\
\hline \multirow{3}{*}{$\begin{array}{l}\text { Preoperative } \\
\text { abdominal US }\end{array}$} & & 106 & $58.2 \%$ & 19 & $46.3 \%$ & 87 & $61.7 \%$ & 0.08 \\
\hline & $\begin{array}{l}\text { Positive } \\
\text { preoperative }\end{array}$ & $\begin{array}{l}70 / \\
106\end{array}$ & $66 \%$ & $\begin{array}{l}10 / \\
19\end{array}$ & $52.6 \%$ & $60 / 87$ & $69.0 \%$ & 0.17 \\
\hline & abdominal US & & & & & & & \\
\hline \multirow[t]{3}{*}{$\begin{array}{l}\text { Preoperative } \\
\text { abdominal CT }\end{array}$} & & 149 & $81.9 \%$ & 38 & $92.7 \%$ & 111 & $78.7 \%$ & $\hat{0.05}$ \\
\hline & $\begin{array}{l}\text { Positive } \\
\text { preoperative }\end{array}$ & $\begin{array}{l}128 / \\
149\end{array}$ & $85.9 \%$ & $\begin{array}{l}35 / \\
38\end{array}$ & $92.1 \%$ & $\begin{array}{l}93 \\
/ 111\end{array}$ & $83.8 \%$ & 0.28 \\
\hline & abdominal CT & & & & & & & \\
\hline $\begin{array}{l}\text { Complicated } \\
\text { appendicitis }\end{array}$ & & 63 & $34.6 \%$ & 17 & $41.5 \%$ & 46 & $32.6 \%$ & 0.30 \\
\hline Time to surgery & & $\begin{array}{l}15.2 \pm \\
1.6\end{array}$ & & $\begin{array}{l}12.9 \pm \\
2.1\end{array}$ & & $\begin{array}{l}15.9 \pm \\
1.9\end{array}$ & & 0.44 \\
\hline Appendectomy & & 160 & $87.9 \%$ & 31 & $75.6 \%$ & 129 & $91.5 \%$ & $\overleftarrow{0.05}$ \\
\hline Ileo-cecal resection & & 14 & $7.7 \%$ & 4 & $9.8 \%$ & 10 & $7.1 \%$ & 0.39 \\
\hline $\begin{array}{l}\text { Negative } \\
\text { exploration }\end{array}$ & & 1 & $0.5 \%$ & - & & 1 & & na \\
\hline $\begin{array}{l}\text { Non-Operative } \\
\text { Management }\end{array}$ & & 6 & & 5 & & 1 & & na \\
\hline $\begin{array}{l}\text { Percutaneous } \\
\text { Drainage }\end{array}$ & & 1 & & 1 & & - & - & na \\
\hline \multirow[t]{2}{*}{ Surgical approach } & Open & 69 & $37.9 \%$ & 28 & $68.3 \%$ & 41 & $29.1 \%$ & \multirow{2}{*}{$\dot{0}_{0.05}$} \\
\hline & Laparoscopic & 113 & $62.1 \%$ & 13 & $31.7 \%$ & 100 & $70.9 \%$ & \\
\hline Conversion rate & & 20 & $17.5 \%$ & 4 & $30.8 \%$ & 16 & $15.8 \%$ & 0.17 \\
\hline \multirow[t]{2}{*}{ Morbidity } & Yes & 64 & $35.2 \%$ & 10 & $24.4 \%$ & 54 & $38.3 \%$ & \multirow[t]{2}{*}{0.10} \\
\hline & No & 118 & $64.8 \%$ & 31 & $75.6 \%$ & 87 & $61.7 \%$ & \\
\hline \multirow{2}{*}{$\begin{array}{l}\text { Infective } \\
\text { complications }\end{array}$} & Yes & 32 & $17.6 \%$ & 6 & $14.6 \%$ & 26 & $18.4 \%$ & \multirow[t]{2}{*}{0.74} \\
\hline & No & 150 & $82.4 \%$ & 35 & $85.4 \%$ & 115 & $81.6 \%$ & \\
\hline \multirow{3}{*}{ Clavien-Dindo 2-4 } & & & $21.4 \%$ & & $14.6 \%$ & & $23.4 \%$ & \multirow[t]{3}{*}{0.32} \\
\hline & Yes & 39 & & 6 & & 33 & & \\
\hline & No & 143 & $78.6 \%$ & 35 & $85.4 \%$ & 108 & $76.6 \%$ & \\
\hline
\end{tabular}




\begin{tabular}{|lllllllll|}
\hline & & Total & $\%$ & $\begin{array}{l}\text { Oldest } \\
\text { old }\end{array}$ & $\%$ & $\begin{array}{l}\text { Elderly } \\
<80\end{array}$ & $\begin{array}{l}\text { \% } \\
\text { value }\end{array}$ & $\begin{array}{c}\text { \% } \\
\text { Mortality }\end{array}$ \\
\cline { 2 - 3 } & Yes & 2 & $1.1 \%$ & 1 & $2.4 \%$ & 1 & $0.7 \%$ & 0.40 \\
& No & 180 & $98.9 \%$ & 40 & $97.6 \%$ & 140 & $99.3 \%$ & \\
\hline
\end{tabular}


Table 3

Univariate and multivariate analysis for Overall complications and Major complications (Clavien-Dindo II-IV)

\begin{tabular}{|c|c|c|c|c|c|c|c|c|}
\hline & \multicolumn{4}{|c|}{ Overall Complications (C-D I-IV) } & \multicolumn{4}{|c|}{ Major complications (C-D II-IV) } \\
\hline & $\begin{array}{l}\mathrm{OR} \\
(95 \% \mathrm{Cl}) \\
\text { univariate }\end{array}$ & $\mathrm{p}$ & $\begin{array}{l}\mathrm{OR}(95 \% \mathrm{Cl}) \\
\text { multivariate }\end{array}$ & $\mathrm{p}$ & $\begin{array}{l}\text { OR } \\
(95 \% \mathrm{Cl}) \\
\text { univariate }\end{array}$ & $\mathrm{p}$ & $\begin{array}{l}\text { OR }(95 \% \mathrm{Cl}) \\
\text { multivariate }\end{array}$ & $\mathrm{p}$ \\
\hline Age (mean) & $\begin{array}{l}0,952 \\
(0,910- \\
0,995)\end{array}$ & 0,031 & & & $\begin{array}{l}0,928 \\
(0,875- \\
0,983)\end{array}$ & 0,012 & & \\
\hline MMPI & $\begin{array}{l}1,075 \\
(1,010- \\
1,145)\end{array}$ & 0,050 & $\begin{array}{l}1,058 \\
(1,009- \\
1,108)\end{array}$ & 0,019 & & $\overrightarrow{0}, 200$ & & \\
\hline INR & & $\overrightarrow{0}, 200$ & & & $\begin{array}{l}2,410 \\
(1,158- \\
5,028)\end{array}$ & 0,019 & $\begin{array}{l}2,126 \\
(1,154- \\
3,917)\end{array}$ & 0,016 \\
\hline $\begin{array}{l}\text { lleo.cecal } \\
\text { resection }\end{array}$ & $\begin{array}{l}3,698 \\
(1,183- \\
11,560)\end{array}$ & 0,037 & & & $\begin{array}{l}8,280 \\
(2,590- \\
3,360)\end{array}$ & $<, 001$ & $\begin{array}{l}0,213 \\
(0,087- \\
0,519)\end{array}$ & 0,001 \\
\hline $\begin{array}{l}\text { Complicated } \\
\text { appendicitis }\end{array}$ & $\begin{array}{l}2,047 \\
(1,087- \\
3,856)\end{array}$ & 0,025 & $\begin{array}{l}0,529 \\
(0,296- \\
0,945)\end{array}$ & 0,031 & $\begin{array}{l}1,629 \\
(0,790- \\
3,856)\end{array}$ & 0,184 & & \\
\hline $\begin{array}{l}\text { Oral } \\
\text { anticoagulants }\end{array}$ & $\begin{array}{l}2,317 \\
(1,169- \\
4,593)\end{array}$ & 0,015 & $\begin{array}{l}0,483 \\
(0,252- \\
0,927)\end{array}$ & 0,029 & $\begin{array}{l}3,038 \\
(1,431- \\
6,958)\end{array}$ & 0,003 & $\begin{array}{l}0,048 \\
(0,202- \\
0,992)\end{array}$ & 0,048 \\
\hline Kidney disease & $\begin{array}{l}2,667 \\
(0,882- \\
8,060)\end{array}$ & 0,133 & & & $\begin{array}{l}2,190 \\
(0,689- \\
8,060)\end{array}$ & 0,184 & & \\
\hline COPD & $\begin{array}{l}1,684 \\
(0,878- \\
3,230)\end{array}$ & 0,115 & & & & $\overrightarrow{0,200}$ & & \\
\hline$A S A \geq 3$ & $\begin{array}{l}1,730 \\
(0,916- \\
3,265)\end{array}$ & 0,015 & $\begin{array}{l}0,502 \\
(0,225- \\
0,990)\end{array}$ & 0,047 & $\begin{array}{l}4,263 \\
(1,766- \\
10,288)\end{array}$ & 0,001 & $\begin{array}{l}0,337 \\
(0,135- \\
0,844)\end{array}$ & 0,020 \\
\hline Age $<80$ & $\begin{array}{l}2,09 \\
(1,138- \\
3,867)\end{array}$ & 0,101 & & & & $\overrightarrow{0,200}$ & & \\
\hline Hypertension & & $\overrightarrow{0,200}$ & & & $\begin{array}{l}1,739 \\
(0,890- \\
3,397)\end{array}$ & 0,103 & & \\
\hline Diabetes $(\mathrm{Y} / \mathrm{N})$ & & $\overrightarrow{0,200}$ & & & $\begin{array}{l}2,083 \\
(1,002- \\
4,333)\end{array}$ & 0,042 & & \\
\hline
\end{tabular}

\section{Discussion}


Life expectancy is increasing and consequently there is an increasing elderly population with multiple concomitant and more severe co-morbidities. $(5,6)$ With this increase of the lifespan, a growing incidence of acute appendicitis has been registered in the elderly ( $\geq 65$ years old) population and also in the oldest old (> 80 years old). $(9,29)$ Moreover, emergency surgery in the elderly is challenging in terms of decision-making, managing co-morbidity and post-operative rehabilitation with high morbidity and mortality rate. $(2,3,7)$ On the light of this, it is pivotal to define the possible clinical-pathological features and treatment of such disease in a well-known frailer portion of the population.

New pathophysiology acknowledgement and improved surgical and anaesthetic skills allowed the surgeon to achieve better results in treating these high-risk patients. (3), However, diagnosis and treatment of acute appendicitis in elderly patients still remain a challenge. (12-15).

We particularly focused on the age-related clinical differences and investigated the role of age as independent risk factor for the main clinical course and outcomes.

We have herein reported, to the best of our knowledge, the largest series of comparison of clinical features and outcomes between patients aged 80 years and older and elderly patients with an age comprised between 65 and 79 years presenting with $A A$, since no series with similar design were found in the current literature. The elderly account for approximately $10 \%$ of the population and between them about a quarter is represented by patient $>80$ years old. Several studies evidenced significant differences in terms of AA clinical course between patients older and younger than 65 years with an increased morbidity and length of stay in the elderly. (12-15) Interestingly enough, in our study population, age $\geq 80$ years was not an independent risk factor for both major and overall morbidities as well as for frailty which surprisingly is not statistically associated with postoperative complications. Focusing on the clinical presentation of $A A$, we found no difference in terms of pre-operative variables such us sex, BMI, BT, MPI and presence of comorbidities between the two groups. Regarding laboratories value, only few studies have investigated the predictive role of preoperative laboratory parameters. $(30,31)$. According to the literature, the age of the patient is one of the most important factor affecting the degree of elevation in inflammatory markers. Although there are many studies that have evaluated the benefits of using WBC, consensus has not yet been reached. $(32,33)$ Moreover, elderly patients have generally less remarkable inflammatory factors, due to decreased immune system response ability. $(34,35)$. At this regard, our study shows no difference in terms of WBC, PCR and glycaemia between the two groups and we evidenced also a similar rate of SIRS and q-SOFA. On the contrary, we reported a significant higher level of lactate and creatinine in the oldest old group. A possible explanation could be linked to the long-terms pre-existing comorbidities in the oldest old group that negatively influence the already reduced physiological functions of elderly patients, leading to an insufficient organ reserve to cope with an inflammatory insult such as AA.

Several studies have shown a higher rate of complicated AA in the elderly group. $(24,36,37)$ This finding may be explained by the fact that elderly patients with perforated appendix would show poor exacerbation of pain as well as more generalized lower abdominal tenderness and guarding leading to a delay in presentation to the hospital. $(38,39)$ This is in line with other studies who report a reduction of pain in oldest old patients, probably linked to a greater capacity to endure or to report it. $(40,41)$

However, our series did not show a significant increase rate of complicated AA in the oldest group, but nevertheless perforation or abscess at presentation are independent risk factors for overall morbidities.

Page $12 / 19$ 
Based on this premise, we can assume that it is absolutely necessary to consider all clinical and laboratory findings, as well as the radiological methods for diagnosing acute appendicitis, above all in the oldest old. According to the recent literature, the role of diagnostic imaging, such as POCUS and CECT is another major controversy. $(14,42)$ In our series, more than half of the patients underwent preoperative POCUS with no difference in terms of positive findings between the elderly and the oldest old group. However, an abdomen CECT scan was done in the $81 \%$ of the patients, reaching a rate of $92,7 \%$ in the oldest-old group. This finding is consistent with the number of ileocolic resection performed, since in the presence of a not clear diagnosis of appendicitis only at CECT (e.i. ileocecal abscess or pseudo inflammatory tumour) a major resection was carried out. The recently published Cochrane systematic review on CECT scan for diagnosis of AA in adults identified 64 studies including 71 separate study populations with a total of 10280 participants (4583 with and 5697 without AA). Summary sensitivity of CECT scan was 0.95 , and summary specificity was 0.94 . At the median prevalence of AA (0.43), the probability of having AA following a positive CECT result was 0.92 , and the probability of having AA following a negative CECT result was 0.04 . (43). According to the last World Society of Emergency Surgery guidelines (WSES), we agree that POCUS is the most appropriate first-line diagnostic tool, however as the elderly have often not typical laboratories values and symptoms unlikely to be acute appendicitis, cross-sectional imaging such us CECT scan is recommended before surgery. (14). Delay in presentation was found by many authors to be the reason behind the higher rate of perforation seen in the elderly population while in a meta-analysis of van Dijk a delaying appendectomy for up to 24 hours after admission does not appear to be a risk factor for complicated appendicitis, SSI or other morbidities. $(44,45)$

Our research showed a slight lower time to surgery in the OOG. This can be interposed in light of the fact that when facing with oldest old, having them a smaller functional reserve, a more timely intervention is needed, and it also run with the greater rate of major resection carried out in this group. However, time to surgery was not a risk factor for overall and major complications. Regarding treatment strategies, even if over the last few years, several reports have been published describing non-operative-management (NOM) of AA, in our series all but seven patients underwent surgical procedure. (46-49) However 6 out of 7 of NOM patients were $>80$ years old. Such findings, reflects the tendency of avoiding surgical procedures in patients generally defined as not fit for surgery.

Appendectomy was the overall most common surgical procedure, the rate of major surgery such as ileocecal resection was similar in both groups and it was an independent risk factor for major post-operative complication at both univariate and multivariate analysis. This could be linked with another evidence emerged from our study which shows how the presence of complicated appendicitis is an independent risk factor for overall and major complications both at univariate and multivariate analysis.

Regarding the surgical approach, several systematic reviews of randomized control trials comparing laparoscopic appendectomy (LA) versus open appendectomy (OA), conclude that LA leads to less postoperative pain, lower overall hospital stays, and significantly decreases postoperative complications, in particular SSI. (14, 51) From our experience, the laparoscopic approach was statistically more frequent in the elderly group. This could be linked to the fact that being the oldest old often less autonomous and often more bedridden, the advantages of laparoscopy are less important.

Of note, according to our analysis, there was no difference regarding the conversion rate in both groups and it was not a risk factor for post-operative morbidity. On the other side, an ASA $\geq 3$ score was an independent 
factor for overall and major complications both at univariate and multivariate analysis, so we can assume that concomitant comorbidities might contribute the most to higher morbidity rate in aged patients.

Focusing on major complications, another important finding of our study is that there was an inverse relationship between increasing age and AA related major complications, highlighted how oldest patients in their frailty, achieve a more stable physiologic status compared to elderly patient with equal comorbidity rate. Moreover, comorbidities such us hypertension, diabetes, use of OAD and kidney dysfunction are independent risk factors for major comorbidity regardless patient age.

Although our study represents, to the best of our knowledge, the largest case series that specifically focuses on the AA clinical course in the over 80-year population, some limitations should be outlined. The observational multicenter cohort design, without a control population to compare is the most important. Another limitation concerns the epidemiological data, that are limited by the number responder centres

However, the prospective data collection and "a priori" definition of criteria to identify postoperative complications might mitigate these limitations. Moreover, a wide multicenter study allows more variables and reproducible results than a single center, while the large series of patients allowed excluding confounders by multiple logistic analyses.

\section{Conclusion}

Our study suggests that age $\geq 80$ years is not an independent risk factor for morbidities. Moreover, no difference in terms of pre-operative variables such as sex, BMI, BT, MPI and presence of comorbidities in the OOG were found. POCUS is safe and effective for the diagnosis of appendicitis in the elderly; however, a CECT is often needed to exclude other age-related diseases such as tumours. Having the oldest old a smaller functional organ reserve, an earlier intervention is needed, especially because they required greater rate of major resection.

\section{Abbreviations}

Frailesel

Frailty and Emergency Surgery in the Elderly

AA

acute appendicitis

AIRS

Appendicitis Inflammatory Response

STROBE

Strengthening the Reporting of Observational Studies in Epidemiology

CRP

C-Reactive Protein

PCT

procalcitonin

ASA

American Society of Anesthesiologists

MPI

Page 14/19 
Mannheim Peritonitis Index

CD

Clavien-Dindo

SIRS

Systemic Inflammatory Response Syndrome

q-Sofa

quick- Sequential Organ Failure Assessment

ICD-9 ${ }^{\text {тм }}$

International Classification of Diseases versions 9

LOS

Length of in-hOspital Stay

CECT

Contrast Enhancement Computerized Tomography

POCUS

Point-of-Care-Ultrasound

IQR

Interquartile Range

OOG

Oldest Old Group

CEG

Control Elderly Group

OAD

Oral Anticoagulant Drugs

BMI

Body Mass Index

BT

Body Temperature

WBC

White Blood Cells Count

Declarations

\section{Ethics approval and consent to participate}

Not applicable

Consent for publication

Not applicable

Availability of data and materials 
The datasets used and/or analysed during the current study are available from the corresponding author on reasonable request.

\section{Competing interests}

The authors declare no potential financial conflict of interest related to this manuscript.

\section{Funding}

This research did not receive any specific grant from funding agencies in the public, commercial, or not-for-profit sectors

\section{Authors' contributions}

PF: Study conception and design, literature search, acquisition, interpretation and analysis of data, drafting and critically revising the article for important intellectual content and final approval of the version to be published. VF: literature search, acquisition, interpretation and analysis of data VC: literature search, acquisition, interpretation and analysis of data GC: acquisition, interpretation and analysis of data, drafting and critically revising the article for important intellectual content and final approval of the version to be published LP: acquisition, interpretation and analysis of data PM: acquisition, interpretation and analysis of data ALG: drafting and critically revising the article for important intellectual content and final approval of the version to be published GS: drafting and critically revising the article for important intellectual content and final approval of the version to be published

\section{Acknowledgement:}

${ }^{4}$ List of Elderly Risk Assessment and Surgical Outcome (ERASO) Collaborative Study Group endorsed by SICUT, ACOI, SICG, SICE, and Italian Chapter of WSES

Agresta F, Alemanno G, Anania G, Antropoli M, Argenio G, Atzeni J, Avenia N, Azzinnaro A, Baldazzi G, Balducci G, Barbera G, Bellanova G, Bergamini C, Bersigotti L, Bianchi PP, Bombardini C, Borzellino G, Bozzo S, Brachini G, Buonanno GM, Canini T, Cardella S, Carrara G, Cassini D, Castriconi M, Ceccarelli G, Celi D, Ceresoli M, Chiarugi M, Cillara N, Cimino F, Cobuccio L, Cocorullo G, Colangelo E, Costa G, Crucitti A, DallaCaneva P, De Luca M, de Manzoni Garberini A, De Nisco C, De Prizio M, De Sol A, Dibella A, Falcioni T, Falco N, Farina C, Finotti E, Fontana T, Francioni G, Fransvea P, Frezza B, Garbarino G, Garulli G, Genna M, Giannessi S, Gioffrè A, Giordano A, Gozzo D, Grimaldi S, Gulotta G, lacopini V, larussi T, Laracca G, Laterza E, Leonardi A, Lepre L, Lorenzon L, Luridiana G, Malagnino A, Mar G, Marini P, Marzaioli R, Massa G, Mecarelli V, Mercantini P, Mingoli A, Nigri G, Occhionorelli S, Paderno N, Palini GM, Paradies D, Paroli M, Perrone F, Petrucciani N, Petruzzelli L, Pezzolla A, Piazza D, Piazza V, Piccoli M, Pisanu A, Podda M, Poillucci G, Porfidia R, Rossi G, Ruscelli P, Spagnoli A, Sulis R, Tartaglia D, Tranà C, Travaglino A, Tomaiuolo P, Valeri A, Vasquez G, Zago M, Zanoni E.

\section{References}


1. Joseph B, Zangbar B, Pandit V. Emergency General Surgery in the Elderly: Too Old or Too Frail? J Am Coll Surg. 2016 May;222(5):805-13.

2. Aucoin S, Mclsaac DI. Emergency General Surgery in Older Adults: A Review. Anesthesiol Clin. 2019 Sep;37(3):493-505.

3. Torrance AD, Powell SL, Griffiths EA. Emergency surgery in the elderly: challenges and solutions. Open Access Emerg Med. 2015 Sep;8:7:55-68.

4. Addition by subtraction

Acute care surgery and emergency general surgery

Bruns BR, Tesoriero RB, Narayan M, O’Meara L, Lauerman MH, Eaton B, Herrera AV, Scalea TM, Diaz JJ. Acute care surgery and emergency general surgery: Addition by subtraction.

5. National Institute on Aging (NIA). (2018) Available at: https://www.nia.nih.gov. Accessed 22 May 2019.

6. ISTAT. Stime per l'anno 2017-2018, Available at: http://www4.istat.it/it/anziani. Accessed April 1, 2019.

7. Desserud KF, Veen T. Søreide K Emergency general surgery in the geriatric patient. Br J Surg. 2016 Jan;103(2):e52-61.

8. Costa G, Massa G, ERASO (Elderly Risk Assessment for Surgical Outcome) Collaborative Study Group. Frailty and emergency surgery in the elderly: protocol of a prospective, multicenter study in Italy for evaluating perioperative outcome (The FRAILESEL Study). Updates Surg. 2018;70:97-104.

9. Ferris M, Quan S, Kaplan BS, Molodecky N, et al. The Global Incidence of Appendicitis: A Systematic Review of Population-based Studies. Ann Surg. 2017 Aug;266(2):237-41.

10. Mahajan P, Basu T, Pai CW. Factors Associated With Potentially Missed Diagnosis of Appendicitis in the Emergency Department. JAMA Netw Open. 2020 Mar 2;3(3):e200612.

11. Ragsdale L, Southerland L. Acute abdominal pain in the older adult. Emerg Med Clin North Am. 2011 May;29(2):429-48. x.

12. Gürleyik G, Gürleyik E. Age-related clinical features in older patients with acute appendicitis. Eur J Emerg Med. 2003 Sep;10(3):200-3.

13. Spangler R, Pham TV, Khoujah D. Abdominal emergencies in the geriatric patient. Int J Emerg Med. $2014 ; 7: 43$.

14. Di Saverio S, Podda M, De Simone B, Ceresoli M, et al Diagnosis and treatment of acute appendicitis: 2020 update of the WSES Jerusalem guidelines. World J Emerg Surg. 2020 Apr 15;15(1):27.

15. Gorter RR, Eker HH, Gorter-Stam MA, Abis GS, et al. Diagnosis and management of acute appendicitis. EAES consensus development conference 2015. Surg Endosc. 2016 Nov;30(11):4668-4690.77.

16. Alvarado A. How to improve the clinical diagnosis of acute appendicitis in resource limited settings. World $\mathrm{J}$ Emerg Surg. 2016;11:1.

17. Deiters A, Drozd A, Parikh P Use of the Alvarado Score in Elderly Patients with Complicated and Uncomplicated Appendicitis. Am Surg. 2019 Apr 1;85(4):397-402.

18. Andersson M, Kolodziej B, Andersson RE. STRAPPSCORE Study Group Randomized clinical trial of Appendicitis Inflammatory Response score-based management of patients with suspected appendicitis. $\mathrm{Br}$ J Surg. 2017 Oct;104(11):1451-61. 
19. Kollár D, McCartan DP, Bourke M, Cross KS, Dowdall J. Predicting acute appendicitis? A comparison of the Alvarado score, the Appendicitis Inflammatory Response Score and clinical assessment. World J Surg. 2015 Jan;39(1):104-9.

20. Ko FC. Preoperative Frailty Evaluation: A Promising Risk-stratification Tool in Older Adults Undergoing General Surgery. Clin Ther. 2019 Mar;41(3):387-99.

21. Khan M, Jehan F, Zeeshan M. Failure to Rescue After Emergency General Surgery in Geriatric Patients: Does Frailty Matter? J Surg Res. 2019 Jan;233:397-402.

22. Park SY, Chung JS, Kim SH, Kim YW, Ryu H, Kim DH. The safety and prognostic factors for mortality in extremely elderly patients undergoing an emergency operation. Surg Today. 2016 Feb;46(2):241-7.

23. Costa G, Fransvea P, Podda M. (Elderly Risk Assessment and Surgical Outcome) Collaborative Study Group. The use of emergency laparoscopy for acute abdomen in the elderly: the FRAILESEL Italian Multicenter Prospective Cohort Study Updates Surg. 2020 Feb 22.

24. Poillucci G, Podda M, Pisanu A. Risk factors for postoperative morbidity following appendectomy in the elderly: a nationwide prospective cohort study. Eur J Trauma Emerg Surg. 2019 Jul 15.

25. von Elm E, Altman DG, Egger M, Pocock SJ, Gøtzsche PC, Vandenbroucke JP, STROBE Initiative. The Strengthening the Reporting of Observational Studies in Epidemiology (STROBE) Statement: guidelines for reporting observational studies. Int J Surg. 2014 Dec;12(12):1495-9.

26. Tracy BM, Wilson JM, Smith RN, Schenker ML, Gelbard RB. The 5-Item Modified Frailty Index Predicts Adverse Outcomes in Trauma [published online ahead of print, 2020 Apr 30]. J Surg Res. 2020;253:167-72.

27. Neri A, Marrelli D, Scheiterle M. Re-evaluation of Mannheim prognostic index in perforative peritonitis: prognostic role of advanced age. A prospective cohort study. Int J Surg. 2015 Jan;13:54-9.

28. Dindo D, Demartines N, Clavien PA. Classification of Surgical Complications: a new proposal with evaluation in a cohort of 6336 patients and results of a survey. Ann Surg 240:205-213.

29. Segev L, Keidar A, Schrier I, Rayman S, Wasserberg N, Sadot E. Acute appendicitis in the elderly in the twenty-first century. J Gastrointest Surg. 2015 Apr;19(4):730-5.

30. Bayrak S, Tatar C, Cakar E, et al. Evaluation of the predictive power of laboratory markers in the diagnosis of acute appendicitis in the elderly. North Clin Istanb. $2019 \mathrm{Jul} ; 8(3): 293-301.6$ (.

31. Boshnak N, Boshnaq M, Elgohary H. Evaluation of Platelet Indices and Red Cell Distribution Width as New Biomarkers for the Diagnosis of Acute Appendicitis. J Invest Surg. 2018 Apr;31(2):121-9.

32. Şahbaz NA, Bat O, Kaya B, Ulukent SC, İlkgül Ö, Özgün MY, et al. The clinical value of leucocyte count and neutrophil percentage in diagnosing uncomplicated (simple) appendicitis and predicting complicated appendicitis. Ulus Travma Acil Cerrahi Derg. 2014;20:423-6. 18.

33. Ishizuka M, Shimizu T, Kubota K. Neutrophil-to-lymphocyte ratio has a close association with gangrenousappendicitis in patients undergoing appendectomy. Int Surg. 2012;97:299-304.

34. Soysal P, Stubbs B, Lucato P. Inflammation and frailty in the elderly: A systematic review and meta-analysis. Ageing Res Rev. 2016 Nov;31:1-8.

35. De Martinis M, Franceschi C, Monti D. Inflammation markers predicting frailty and mortality in the elderly. Exp Mol Pathol. 2006 Jun;80(3):219-27.

36. Cohen-Arazi O, Dabour K, Bala M. Management, treatment and outcomes of acute appendicitis in an elderly population: a single-center experience. Eur J Trauma Emerg Surg. 2017 Oct;43(5):723-7. 
37. Andert A, Alizai HP. Klink CD Risk factors for morbidity after appendectomy. Langenbecks Arch Surg. 2017 Sep;402(6):987-93.

38. Canal C, Lempert M, Birrer DL. Short-term outcome after appendectomy is related to preoperative delay but not to the time of day of the procedure: A nationwide retrospective cohort study of 9224 patients. Int J Surg. 2020 Apr;76:16-24.

39. Alore EA, Ward JL, Todd SR, et al. Population-level outcomes of early versus delayed appendectomy for acute appendicitis using the American College of Surgeons National Surgical Quality Improvement Program. J Surg Res. 2018 Sep;229:234-42.

40. Mallon T, Ernst A, Brettschneider C, et al for the AgeCoDe \& AgeQualiDe study group Prevalence of pain and its associated factors among the oldest-olds in different care settings - results of the AgeQualiDe study BMC Fam Pract. 2018; 19: 85.

41. Schofield P. The Assessment of Pain in Older People: UK National Guidelines Age Ageing. 2018 Mar; 47(Suppl 1): i1-i22.

42. Sammalkorpi HE, Leppäniemi A, Lantto E, Mentula P. Performance of imaging studies in patients with suspected appendicitis after stratification with adult appendicitis score. World J Emerg Surg. 2017;12:6.

43. Rud B, Vejborg TS, Rappeport ED, et al Computed tomography for diagnosis of acute appendicitis in adults. Cochrane Database Syst Rev. 2019 Nov 19;2019(11).

44. Abdelkarim H, Omari, Muhammad R, Khammash, et al. Acute appendicitis in the elderly: risk factors for perforation. World J Emerg Surg. 2014;9:6.

45. van Dijk ST, van Dijk AH, Dijkgraaf MG, Boermeester MA. Meta-analysis of in-hospital delay before surgery as a risk factor for complications in patients with acute appendicitis Br. J Surg. 2018 Jul;105(8):933-45.

46. Harnoss JC, Zelienka I, Probst P. Antibiotics Versus Surgical Therapy for Uncomplicated Appendicitis: Systematic Review and Meta-analysis of Controlled Trials (PROSPERO 2015: CRD42015016882). Ann Surg. 2017 May;265(5):889-900.

47. Yang Z, Sun F, Ai S. Meta-analysis of studies comparing conservative treatment with antibiotics and appendectomy for acute appendicitis in the adult. BMC Surg. 2019 Aug;14(1):110. 19(.

48. Sakran JV, Mylonas KS, Gryparis A. Operation versus antibiotics-The "appendicitis conundrum" continues: A meta-analysis. J Trauma Acute Care Surg. 2017 Jun;82(6):1129-37.

49. Podda M, Cillara N, Di Saverio S. Antibiotics-first strategy for uncomplicated acute appendicitis in adults is associated with increased rates of peritonitis at surgery. A systematic review with meta-analysis of randomized controlled trials comparing appendectomy and non-operative management with antibiotics. Surgeon. 2017 Oct;15(5):303-14.

50. Wang D, Dong T, Shao Y. Laparoscopy versus open appendectomy for elderly patients, a meta-analysis and systematic review. BMC Surg. 2019 May 28;19(1):54.

51. Hori T, Machimoto T, Kadokawa Y. Laparoscopic appendectomy for acute appendicitis: How to discourage surgeons using inadequate therapy. World J Gastroenterol. 2017 Aug;28(32):5849-59. 23(. 